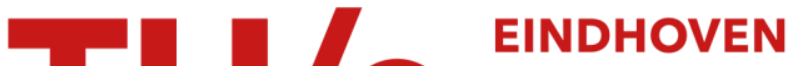 UNIVERSITY OF TECHNOLOGY
}

\section{Profit and risk evaluation in customer driven engineering and manufacturing}

Citation for published version (APA):

Muntslag, D. R. (1994). Profit and risk evaluation in customer driven engineering and manufacturing. International Journal of Production Economics, 36(1), 97-107. https://doi.org/10.1016/0925-

5273\%2894\%2990152-X, https://doi.org/10.1016/0925-5273(94)90152-X

DOI:

10.1016/0925-5273\%2894\%2990152-X

10.1016/0925-5273(94)90152-X

Document status and date:

Published: 01/01/1994

\section{Document Version:}

Publisher's PDF, also known as Version of Record (includes final page, issue and volume numbers)

\section{Please check the document version of this publication:}

- A submitted manuscript is the version of the article upon submission and before peer-review. There can be important differences between the submitted version and the official published version of record. People interested in the research are advised to contact the author for the final version of the publication, or visit the $\mathrm{DOI}$ to the publisher's website.

- The final author version and the galley proof are versions of the publication after peer review.

- The final published version features the final layout of the paper including the volume, issue and page numbers.

Link to publication

\section{General rights}

Copyright and moral rights for the publications made accessible in the public portal are retained by the authors and/or other copyright owners and it is a condition of accessing publications that users recognise and abide by the legal requirements associated with these rights.

- Users may download and print one copy of any publication from the public portal for the purpose of private study or research.

- You may not further distribute the material or use it for any profit-making activity or commercial gain

- You may freely distribute the URL identifying the publication in the public portal.

If the publication is distributed under the terms of Article 25fa of the Dutch Copyright Act, indicated by the "Taverne" license above, please follow below link for the End User Agreement:

www.tue.nl/taverne

Take down policy

If you believe that this document breaches copyright please contact us at:

openaccess@tue.nl

providing details and we will investigate your claim. 


\title{
Profit and risk evaluation in customer driven engineering and manufacturing
}

\author{
Dennis R. Muntslag ${ }^{1}$ \\ Graduate School of Industrial Engineering and Management Science, Eindhoven University of Technology, P.O. Box 513, 5600 MB \\ Eindhoven, The Netherlands
}

\begin{abstract}
In engineer-to-order production situations quotation prices of customer driven engineering and manufacturing projects are normally determined by calculating a full cost price. In this article we shall argue that the use of a full cost price does not appear to be worthwhile in view of the specific characteristics of this type of production situation. Furthermore we propose an alternative way of determining and evaluating quotation prices. Instead of calculating a full cost price we suggest to evaluate the profit margin and risk level of these kind of projects. The price level of a potential order can be reviewed by evaluating the potential (gross) contribution to profit of the potential order as soon as this price level is known. The potential (gross) contribution to profit is calculated by subtracting the direct allocatable costs of the potential order from the price level dictated by the market. This potential contribution to profit can be expressed as a percentage of the price level (potential profit margin). The price level is evaluated by comparing the potential margin to a target margin. This target margin has been established based upon the company business strategy using a risk management and profit differentiation point of view.
\end{abstract}

\section{Introduction}

This article focuses on a specific subset of production situations, namely engineer-to-order production plants [1] which produce industrial equipment. This type of customer driven engineering and manufacturing plant is concerned with the engineering and production of complex industrial equipment based upon customer orders. A typical control characteristic of these production situations is uncertainly.

\footnotetext{
${ }^{1}$ Works also as a senior consultant for Moret Ernst \& Young Management Consultants.
}

In general we can identify three uncertainty factors [2] namely:

(1) product mix and volume uncertainty,

(2) product specification uncertainty (parts of the product specifications have not yet been finalized and are customer specific),

(3) process specification uncertainty (it is difficult to estimate the amount and types of resource capacity which will be required by a specific customer order).

Due to these types of uncertainty it is difficult to calculate a good quotation price, because parts of the product and process specifications are unknown. Normally, in this type of production 
situation, the quotation prices are determined by calculating a full cost price. In this article we shall argue that using this method of calculating cost prices does not provide any added value. On the contrary, it can lead to wrong pricing decisions. Furthermore we shall propose an alternative way of determining quotation prices that will better fit the specific characteristics of the engineer-to-order production situation.

In Section 2 we shall first describe the engineer-toorder characteristics in more detail. In Section 3 we shall discuss the way in which customer driven engineering and manufacturing projects are calculated. Furthermore we shall discuss the deficiencies of using a full cost price in these situations. A new approach in calculating these projects is presented in Section 4.

\section{Engineer-to-order manufacturing}

Engineer-to-order plants operate in a market which can be characterized as being extremely dynamic. Another characteristic of this market is the large degree of uncertainty which is due to unknown sales volumes and unknown product specifications for future orders. An important aspect of this type of firm is that a significant portion of the products produced by these plants must be engineered according to customer specifications. This engineering process which precedes the actual manufacturing of the product is referred to here as customer order driven engineering [3]. The type of production organization chosen here produces complicated and complex configurations of industrial equipment consisting of thousands of components. It is assumed that major investments have been made in developing products independently from the actual customer orders. Nevertheless, the customer is still in a position to be able to influence the choice and design of a significant portion of the product components and to influence the functionality of the product by providing specifications for customization. The products chosen here are capital goods which represent major capital investments for industrial customers. The demand for these products depends to some extent on the economic climate. This means that sales may vary widely from one period to the next. Forecasting the demand, even at the product type level, is extremely difficult since the products are partially custombuilt. There is a great deal of competition in terms of price as well as quality. This conclusion is supported by the fact that the number of order quotations is much larger than the number of customer orders actually placed.

Each customer order can be viewed as a project with a project network structure consisting of numerous activities to be performed. Examples of these activities are engineering, process planning, component manufacturing and assembly. Normally, more than one project is in production at any given point in time. The manufacturing of components is set up along functional lines using flexible manufacturing equipment in view of the general uncertainty regarding what product will be produced and the customized aspects of the product. In view of the size of projects, it is not possible to dedicate human resources to a specific project for a given period of time according to the generally accepted principles for a project organization. This means that a worker within the functional organization may be working on more than one project at the same time during the same period. The primary chain of production activities to be controlled can be split up into two major streams or stages of activities: a nonphysical stage and a physical stage. The nonphysical stage includes the quotation phase, the custom engineering of the product and the process planning activities. The global flow of goods within an engineer-to-order production plant is shown in Fig. 1.

A possible customer order starts with an initial contact with a potential customer and one of the sales channels (agents, sales office) during the sales lead phase. It is assumed that the customer has a problem and is interested in finding out whether the company can provide a solution. The salesman forms an opinion about the customer's requirements and determines to what extent a solution can be provided. If the customer requires a (detailed) quotation and the salesman believes that there is a good chance of winning the order, then the customer's requirements are documented using a standard sales order checklist. This request for a detailed quotation is then passed on to the internal 


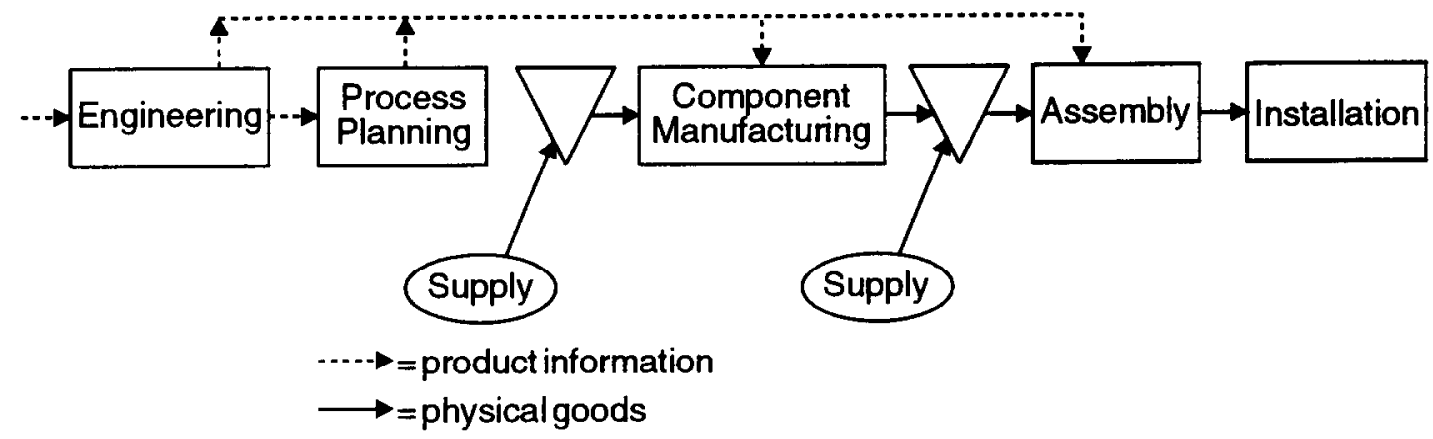

Fig. 1. Global flow of goods for engineer-to-order manufacturing.

Sales Division which gives this to the Engineering Division. This initiates the formal quotation phase.

The request for quotation is received by the Engineering Division and then evaluated and processed by a product engineer. The product specifications are only worked out in general terms at this stage in the form of a general technical description. This document is a summary of the customer requirements translated into product functions and provides the technical content for preparing a detailed quotation. At this moment in the total process a decision is made about the quotation price. After the price is established and a delivery date is determined, the quotation is then sent to the customer. The sales organization is then responsible for negotiating the contract details with the customer. One or more of the quotations to solve a customer's problem will ultimately lead to either a customer order or a breakdown in the negotiations. If the customer decides to place an order, then the order phase is initiated and the customer order can be produced.

After the existence of a new customer order is made known within the organization, the Engineering and Design Department works out the order specifications in more detail in terms of technical drawings, bill-of-materials and further product specifications. Manufacturing instructions first need to be prepared, to the extent that these instructions are not already available, before the physical manufacturing of the customized components can be initiated. These instructions include the selection of operations, machines and tooling, as well as an indication of the operation times. These last activities are carried out within the Process Planning Department.

The physical flow of goods consists of the physical production and purchasing activities. These activities can be initiated as soon as the previously mentioned nonphysical activities have been (partially) completed. A significant portion of the components are purchased; even whole machine modules, often based upon customer specifications, are sometimes purchased as a part of a customer order. Purchase orders for components and subassemblies, as well as the arrangements for outsourcing of production capacity, are coordinated via the Purchasing \& Production Control Department. The components and simple sub-assemblies which are neither purchased nor outsourced are produced internally within the various manufacturing departments. The final customized product is assembled within the Assembly Section. The machine is extensively tested after the assembly phase using test materials (such as boxes, bottles, etc.) provided by the customer. After testing, the machine is partially disassembled and then shipped to the customer. The On-site Installation Department is responsible for the final installation and start-up at the customer's plant.

\section{Calculating costs of potential projects}

\subsection{Calculating under uncertainty}

Three types of uncertainty can be identified as indicated in Section 1. The concepts of uncertainty 
and risk are closely related and are often used interchangeably. The term risk is used in this article to refer to a situation in which various, mutually exclusive events may occur, each leading to a substantially different result in terms of quality, timeliness and cost. A distinction can be made between three types of order-dependent risk, which may have a certain dependency, when this definition of risk is translated to an engineer-to-order situation.

(1) Technical or quality risk: The chance that (a part of) a product cannot be produced, technically, according to the initial estimates. This leads to a situation in which significantly more product engineering and detail design hours are required in the order phase than were originally estimated in the quotation phase. The assumption is that a technically acceptable solution can always be found. The technical risk generally leads to the other two types of risk.

(2) Time risk: The chance that the throughput time required for the engineering and manufacturing of the product is longer than was originally estimated in the quotation phase. As a result, the agreed delivery date for the customer order may not be achievable. The time risk may be caused by a technical risk, but it could also be caused by other factors.

(3) Financial risk: The chance that the cost of the engineering and manufacturing of the product will be more than originally estimated in the quotation phase. This may be caused by a technical risk and/or time risk, but could also be caused by other factors.

Three types of uncertainty can be identified as indicated in Section 1. These types of uncertainty may include one or more of the above-mentioned risks. A further explanation of the relationship between the types of uncertainty and the types of risk is presented here.

\subsubsection{Product uncertainty and risk}

The exact product specifications are not yet known in the quotation phase. A general product concept is developed and an estimate is provided of the number of hours which will be required to complete the detailed design of the product in the order phase. This uncertainty can lead to a technical risk if it becomes apparent during the order phase that the product concept is incomplete or incorrect, or that more hours are needed to complete the detailed design than originally anticipated. This means that additional engineering and/or detailed design hours will be required to solve the unexpected technical problem. A technical risk may thus automatically lead to a financial risk (higher costs resulting from more hours than originally budgeted) and a time risk (the likelihood for a longer internal throughput time).

\subsubsection{Process uncertainty and risk}

Due to the presence of product uncertainty, it is extremely difficult to estimate the amount and types of resource capacities which will be required to produce the product. The required types of resource capacity, in particular, are uncertain. In practice, a large variation is found with respect to the types and number of operations required. This may result in a situation in which there are a sufficient number of hours available to meet requirements in terms of total hours, but that the available capacity per type of operation is completely wrong. This process uncertainty may lead to a time risk if the execution of certain operations implies a longer delay. In addition, this may lead to a financial risk if more work needs to be outsourced and certain internal resource capacities are underutilized to a greater degree than originally anticipated.

\subsubsection{Uncertainty and risk with respect to product mix and volume}

A reliable detailed forecast of the sales demand is extremely difficult to produce in view of the customization aspect in this market. An important uncertainty factor in this respect is the point in time at which the customer order is received. In view of the competitive market and the relatively low probability of quotations becoming orders, the company will always be in a situation in which the number of quotations issued exceeds the number of actual customer orders received. It is generally not known whether a potential customer will place an order based upon a quotation and, if an order is placed, when this will be done. This means that it is difficult to determine when to reserve production capacity. The uncertainty with respect to product mix and volume can lead to a time risk when, for 
example, there is a higher sales volume than originally forecasted in a given period. This can lead to additional financial risk when penalty clauses are enforced or additional outsourcing is required.

\subsection{Calculating a quotation price}

A quotation price is determined for each quotation during the customer order driven engineering. This is an extremely important decision from a financial point-of-view. At this point the company creates an external commitment (to the customer). In particular, the quotation specifies what will be delivered (the quality factor) for what price (the cost factor) and within what delivery lead time (the timeliness factor). Decisions concerning the quotation price are made in the face of a relatively large amount of uncertainty (next to the uncertainties mentioned above), namely:

(1) the point in time at which a quotation may be accepted by the customer and converted to a firm order is unknown and may vary widely,

(2) a large number of the quotations never become orders; the success rate for the quotations in these production situations is approximately $15 \%$, on the average,

(3) the detailed design for parts of the product will be complete only after the firm order is received since part of the product is customized. The product description is worked out to a certain level of detail during the quotation phase, but at this level there will always be a certain amount to technical risk. It is possible that it will be discovered at a later stage that the envisioned product concept is not feasible or can only be realized by incurring (significantly) higher costs over a longer throughput time.

The quotation price which is used as the basis for the ultimate selling price determines, to a large extent, the profit margin for a customer order. A cost price calculation in the form of an order budget can play an important role in determining the quotation price. Other factors and other information such as the market situation and the positioning of the company in the market are also important, of course, in determining the quotation price.
A number of different methods for calculating cost prices can be identified. Several examples of such methods are the burden method, the equivalent amount method, the cost center method and activity-based costing $(\mathrm{ABC})[4,5]$. In determining a full, or integral, cost price, all of the costs associated with the engineering and manufacturing of a product are allocated to the potential order. This means that the indirect costs as well as the direct costs are to be included. The various methods of calculating cost prices differ primarily with respect to the way in which the indirect costs are allocated to a product.

Much attention has been paid to improving the accuracy of allocating indirect costs in recently published studies. An important development in connection with this has been the introduction of $\mathrm{ABC}$ costing (see for example, $[6,7]$ ). A variety of allocation formulas are used in an $A B C$ system in order to achieve a more accurate allocation of indirect costs that in a situation in which only a simple cost allocation scheme is used. More accuracy suggests that the allocations will need to be carried out at a more detailed level.

In this type of production situation, the quotation prices are determined in part by calculating a full cost price based upon average hourly rates with surcharges for allocating the indirect costs. A similar method based upon multiple surcharges [4] is often used in practice, even by larger companies which produce a wide range of different products [8].

\subsection{Why not use a full cost price?}

In view of the simplicity of the chosen full cost approach and the method used for allocating costs, however, there is little causal relationship between the indirect costs and the product at hand. In addition, the actual control effort and the actual use of indirect resources may vary radically between product groups as well as between orders in view of the diversity of products (particularly between product groups) in this type of production situation. Use of this method of calculating cost prices and the "arbitrary" allocation of indirect costs means that certain product groups may be burdened with excessive costs while a fair share of these costs is not allocated to other product groups (see also [9]). 
A number of arguments can be brought forward to support the conclusion that the allocation of indirect costs to possible customer driven engineering and manufacturing projects as currently done in engineer-to-order firms does not provide any added value:

(1) in view of the radically different products and product groups in this type of production situation, it is virtually impossible to establish a causal relationship between a number of indirect cost categories and a potential customer order. Examples of these indirect cost categories include data processing costs, office space and the costs associated with customer order independent engineering. An arbitrary (detailed) allocation of these costs has no value with respect to predicting the actual costs of a customer order,

(2) the final price level in these production situations is dictated to a large extent by market conditions and is, thus, not determined by the company based upon the cost price. It is therefore not necessary to calculate an accurate and detailed full cost price for this purpose,

(3) the extent of the uncertainty in most engineer-to-order firms is such that there is very little knowledge of the product volume and mix regarding the future orders. If costs are allocated arbitrarily, then it is certainly not useful to do this at a detailed level in view of the uncertainties.

In conclusion, the calculation of a full cost price to be used as the basis for determining a quotation price does not appear to be worthwhile in engineer-to-order firms in view of the fact that the price level of a potential order is dictated primarily by market conditions and that the allocation of indirect costs to potential orders cannot be done reliably.

\section{An alternative approach: profit and risk evaluation}

\subsection{Risk management and profit differentiation}

As a basis for effective pricing decisions we introduce the concepts of risk management and profit differentiation within engineer-to-order firms. As described above, the forms of uncertainty which are apparent in an engineer-to-order production situation lead to technical, time and financial risks. Requests for quotation as well as customer orders may vary widely with respect to the degree of (primarily, product) uncertainty. This means that requests for quotation as well as customer orders may have a wide range of (potential) risks. In engineer-to-order firms, it is primarily the technical risk which determines the extent of the financial risk.

To anticipate the wide range of (potential) risks a number of risk categories should be defined based upon the degree of technical risk for the purpose of risk management. A type of portfolio management can then be used in this situation (cf. portfolio theory in the field of finance and treasury management $[10-12]$ ). Following this approach, certain percentages of the projected sales are allocated, periodically, to the various risk categories. In this way the acceptance of too many customer orders in a high (technical) risk category can be prevented. A policy is effectively established in this way which governs the maximum technical risk which is allowed to exist in the portfolio, expressed in terms of the relative sales per risk category. The realized sales in each risk category as compared to the projected sales and the contents of the quotation portfolio (expressed in the same form) thus becomes important decision support information for making control decisions.

In addition to a proper portfolio management, risk management is carried out based upon a differentiation in the profit margins between the risk categories. The realization of a certain annual profit margin is the ultimate goal at the company level. This profit margin is based upon the acquisition and realization of a certain number of customer orders each year. A certain profit (the target profit margin) must also be realized for each order; this is equal to the revenue minus the costs. The company's business stratcgy is translated into a certain profit margin which is budgeted each year for the total organization in terms of a total margin based upon the projected sales revenue. The total margin can then be differentiated by product market combination (PMC) in accordance with the company's product/market strategy. 
Table 1

Distribution of projected sales and targets per PMC/risk category (an example)

\begin{tabular}{llllll}
\hline & PMC I & & PMCII \\
\cline { 2 - 3 } \cline { 5 - 6 } & $\begin{array}{l}\text { Risk category A } \\
\text { (high) }\end{array}$ & $\begin{array}{l}\text { Risk category B } \\
(\text { low) }\end{array}$ & & $\begin{array}{l}\text { Risk category A } \\
\text { (high) }\end{array}$ & $\begin{array}{l}\text { Risk category B } \\
\text { (low) }\end{array}$ \\
\hline Projected sales & 10 million & 20 million & & 15 million & 25 million \\
Target profit margin & $8 \%$ & $8 \%$ & $10 \%$ & $10 \%$ \\
Extra margin to cover extra risk & $4 \%$ & - & $5 \%$ & - \\
Total target margin & $12 \%$ & $8 \%$ & $15 \%$ & $10 \%$ \\
\hline
\end{tabular}

A higher (financial) risk with respect to a (potential) customer order means that there is a greater likelihood that the cost of the customer order will turn out to be higher than originally estimated in the quotation phase, leading to a lower profit margin. Risk management takes this into account by requiring an extra profit margin in addition to the normal profit margin for the orders which fall into a higher risk category. This extra profit margin should be equal to the expected financial risk in the event that the technical risk becomes a fact. An example of this type of profit margin differentiation is presented in Table 1. The assumption here is that there are two PMC's, each one divided into two risk categories. The projected sales revenue and the target margins corresponding to the desired profit levels are worked out for each PMC/risk category combination.

A differentiation by market situation (e.g., positive or negative economic climate) is also desired in addition to the differentiation by risk category. When the economic climate is poor, a lower margin may be appropriate in order to ensure that sufficient sales can be realized. This implies that an important premise in connection with the cost control in engineer-to-order production situations is a policy decision regarding the sales levels and the target profit margins per PMC/risk category/ market situation which should be achieved.

\subsection{Determining a quotation price}

Instead of calculating a full cost price we suggest to evaluate the price level as a basis for negotiations with the potential customer. The price level of a potential order can be reviewed by evaluating the potential (gross) contribution to profit of the potential order as soon as this price level is known. The potential (gross) contribution to profit is calculated by subtracting the direct allocatable costs of the potential order from the price level dictated by the market. This potential contribution to profit can be expressed as a percentage of the price level (potential profit margin). The price level is evaluated by comparing the potential margin to a target margin which has been established based upon the company business strategy and pricing policy (see Fig. 2).

The target margin established based upon the company business strategy and pricing policy serves to:

(1) cover the other, general costs which are incurred in connection with activities related to the various customer orders,

(2) establish a reference point for ensuring that a certain minimum margin is realized with respect to the customer order.

A differentiation is made for each PMC/risk category with respect to the minimum margin for a customer order as a result of the PMC strategy and the chosen approach for risk management (see Table 1). The portion of the total target profit margin per PMC/risk category which is used to cover the other (indirect) costs can be determined by allocating these costs to the various $\mathrm{PMC}$ /risk categories. In contrast to individual projects, a causal relationship can be found between the other indirect costs and the activities associated with the group of projects falling within a specific PMC/risk 


\section{POTENTIAL ORDER}

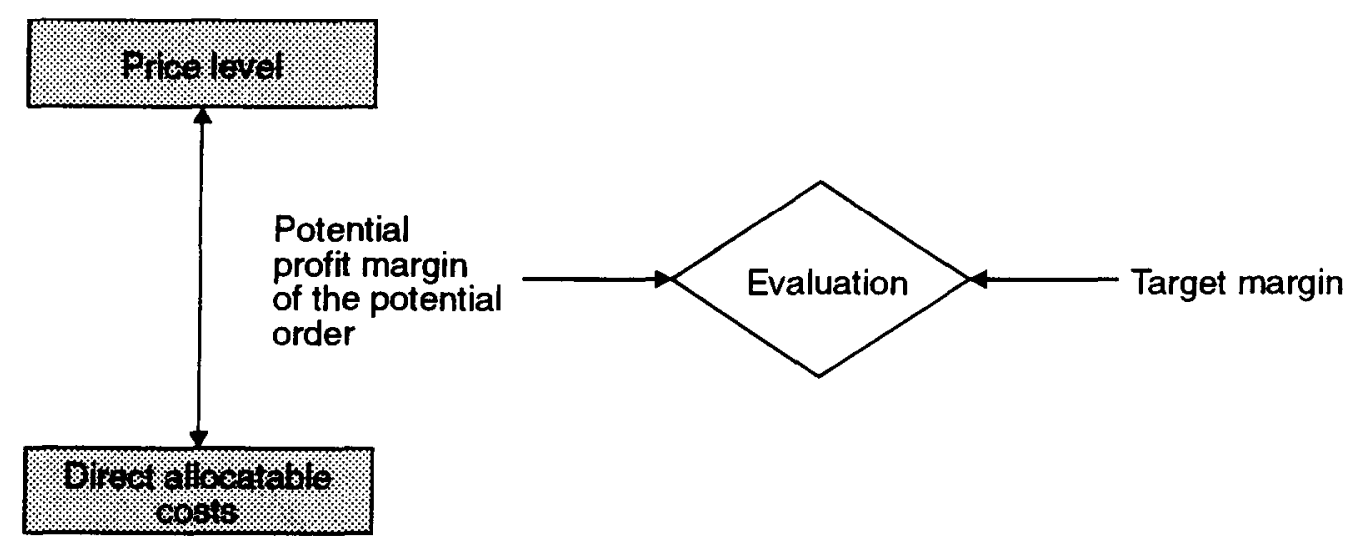

Fig. 2. Evaluating the price level of a potential project

category combination or associated with the organization as a whole.

This first category of indirect costs which have a causal relationship with a PMC/risk category combination is allocated directly. Examples of these costs include:

(1) sales and marketing expenses associated with the various geographically distributed sales offices. These costs can be allocated to specific PMC's,

(2) costs associated with the engineering resource capacity. More engineering resource capacity is generally spent on quotations involving a greater technical risk. A larger portion of these costs is allocated to categories with higher risk.

The second category of indirect costs which have a causal relationship with the company as a whole is allocated to the PMC/risk category combinations based upon the distribution of projected sales revenue. In view of the general nature of these costs, they should be allocated proportionally based upon the distribution of the projected sales revenue such that no differentiation is made based upon PMC/risk category combination. In this way, each dollar of revenue contributes to the coverage of these costs to the same extent.

After the two categories of indirect costs have been allocated to the various PMC/risk category combinations, the margin can be determined for indirect costs (as a percentage of the projected sales) and, subsequently, the total target profit margin can be calculated for each PMC/risk category combination. The determination of the total target profit margin per $\mathrm{PMC} /$ risk category combination is presented in Table 2, using the example from Table 1.

As explained in detail in the previous section, the price level of the quotation is dictated to a large extent by the market and is dependent upon factors such as the current market situation and competitive positioning. The financial consideration which precedes the issuing of a quotation, thus, is not particularly concerned with setting the quotation price, but is concerned instead with evaluating the contribution to profit which could be expected from the potential order, given the price level dictated by the market. This potential contribution to profit is calculated based upon the difference between the price level and the costs which would be directly related to processing the customer order if it is placed by the customer (refer also to Fig. 2), expressed as a percentage of the price level. This is then compared with the established target profit margin for the respective PMC/risk category combination. The decision of whether to issue the quotation at the dictated price level is based upon this evaluation of the potential contribution and an evaluation of the current situation, taking into consideration all of the important factors of market situation, competitive positioning, the status of other quotations issued in the same period and the 
Table 2

Determining the total target margin (an example)

\begin{tabular}{|c|c|c|c|c|}
\hline & \multicolumn{2}{|l|}{ PMC I } & \multicolumn{2}{|l|}{ PMCII } \\
\hline & $\begin{array}{l}\text { Risk category A } \\
\text { (high) }\end{array}$ & $\begin{array}{l}\text { Risk category B } \\
\text { (low) }\end{array}$ & $\begin{array}{l}\text { Risk category A } \\
\text { (high) }\end{array}$ & $\begin{array}{l}\text { Risk category B } \\
\text { (low) }\end{array}$ \\
\hline Projected sales & 10 million & 20 million & 15 million & 25 million \\
\hline Indirect costs (based on sales revenue) & 1 million & 2 million & 1.5 million & 2.5 million \\
\hline Indirect costs (based on causal relationships) & 2 million & 1 million & 2.5 million & 1.5 million \\
\hline Burden percentage indirect costs & $30 \%$ & $15 \%$ & $28 \%$ & $16 \%$ \\
\hline Target profit margin & $12 \%$ & $8 \%$ & $15 \%$ & $10 \%$ \\
\hline Total target margin & $42 \%$ & $23 \%$ & $43 \%$ & $26 \%$ \\
\hline
\end{tabular}

firm customer orders which have been received. The ultimate selling price for the customer order is established as a result of the pricing policy which is subsequently followed and the negotiations with the customer.

\subsection{Allocation of direct costs to potential projects}

In this subsection an example of the different types of direct allocatable costs and the way in which these costs are allocated to potential orders is described. The types of costs included in this example are the cost of:

(1) materials,

(2) detailed design resource capacity,

(3) direct internal and external manufacturing capacity.

\subsubsection{Cost of materials}

Based upon the preliminary draft of the product, an estimate is made of the cost of the materials which will be required to produce the product. The available standard product modules are used in connection with this as much as possible since it is known (often in detail) what quantity of which materials are required to produce the standard product modules. The costs of materials can be allocated directly to the potential order.

\subsubsection{Cost of detailed design resource capacity}

In this example this type of resource capacity is the bottleneck capacity in the order phase and is, therefore, assumed to be $100 \%$ utilized. Based upon this assumption, the cost price per hour can be calculated for this type of resource capacity. All of the costs which are directly related to the detailed design resource capacity should be included here, such as floor space, computer and other equipment, lighting, etc. The detailed design resource capacity reserved for customer order independent engineering is not included here and is not allocated to the potential orders. The costs related to this activity are covered by the margin. The cost of detailed design resource capacity can be calculated for each quotation (based upon hourscost price) using the estimate of the detailed design resource capacity requirements which is specified for each request for quotation.

\subsubsection{Cost of direct internal/external manufacturing capacity}

The size of the internal manufacturing capacity has been kept to a minimum level in most of the engineer-to-order firms in view of possibly depressed market conditions. This means that the utilization of this capacity will be extremely high, e.g., between $90 \%$ and $95 \%$, for the year as a whole. Based upon this assumption, a cost price per hour can be calcuated. Here, too, all of the costs related to the internal manufacturing capacity can be included. A similar approach can be taken with respect to the internal assembly capacity. In this case, however, the option of outsourcing is never considered. When necessary, temporary employees 
are hired to carry out a number of the simpler assembly tasks.

In contrast to internal manufacturing capacity, the external (flexible) manufacturing capacity is seen as being variable rather than fixed. Flexible external manufacturing capacity is used only for a limited period of time in the event that there is insufficient internal resource capacity. Due to the prevailing uncertainty in the quotation phase, it is impossible to determine to what extent a potential order will need to be produced in a period in which external manufacturing capacity will be required. As a result, it is impossible to allocate these costs directly to a potential order. From a manufacturing engineering point-of-view, it makes no difference whether internal or external manufacturing hours are used to process a customer order. In calculating the potential contribution to the profit, it is sufficient to use a weighted average cost price per hour for the manufacturing capacity. The total requirements for external capacity are forecasted annually and an estimate is made of the related costs. This is based partially on the sales forecasts and the historical data related to external capacity requirements. The cost of external manufacturing capacity can be expressed in terms of a cost price per hour. When both the internally available manufacturing capacity and a forecast of the required external manufacturing capacity are known, then a weighted cost price calculation for the use of manufacturing capacity can be made. The cost price for using external manufacturing capacity is higher than the cost price for internal manufacturing capacity in this example. This would normally be expected. The manufacturing cost for each quotation can be calculated (based upon hours $x$ weighted cost price per hour) using the estimated manufacturing capacity requirements associated with each request for quotation. A similar approach can be followed for calculating the cost price per hour for the assembly capacity.

\section{Conclusions}

In this article we have proposed an alternative way of determining and evaluating the quotation price. Instead of calculating a (detailed) full cost price we propose to evaluate the profit and risk level of the project comparing the potential margin to a target margin. From a risk management point of view and because of the existing uncertainties we recommend to differentiate target margins between different PMC/risk categories.

The alternative approach described in this article consists of elements of other existing approaches, namely:

(1) a direct costing approach at the individual project level,

(2) a differentiation of the contribution margin per PMC using a product/market strategy,

(3) a risk management concept using different risk categories with different margins to cover extra risk,

(4) $\mathrm{ABC}$ principles at the project group level for allocating indirect costs to types of projects based on certain causal relationships.

Because of the specific characteristics of customer driven engineering and manufacturing projects in engineer-to-order firms this is a more effective way of controlling the real profit margin of customer orders and as a result the overall annual profit margin at company level.

\section{References}

[1] Sari, J.F., 1981. The MPS and the Bill of Material go hand-in-hand. Richard C. Ling, Inc.

[2] Bertrand, J.W.M. and Muntslag, D.R., 1993. Production control in engineer-to-order firms. Int. J. Prod. Econom., 30-31: 3-22.

[3] Muntslag, D.R., 1993. Managing customer order driven engineering, an interdisciplinary and design oriented approach. Ph.D. Thesis, Eindhoven University of Technology.

[4] Horngren, C.T. and Foster, G., 1991. Cost Accounting: a Managerial Emphasis. Prentice-Hall, Englewood Cliffs, N.J.

[5] Blommaert, A.M.M. and Blommaert, J.M.J., 1991. Bedrijfseconomische analyses. Stenfert Kroese (in Dutch).

[6] Cooper, R., 1988a. The rise of activity-based costing - Part One. What is an activity-based cost system? J. Cost Mgmt. Manuf. Ind: 45-54.

$\lceil 7\rceil$ Cooper, R., 1988b. The rise of activity-based costing - Part Two. When do I need an activity-based cost system? J. Cost Mgmt. Ind: 41-48. 
[8] Howell, R.A., Brown, J.D., Soucy, S.R. and Seed III, A.H., 1987. Management Accounting in the New manufacturing Environment. Montvale.

[9] Cooper, R. and Kaplan, R.S., 1987. How cost accounting systematically distorts product cost, in: W.J. Bruns and R.S. Kaplan (Eds), Accounting \& Management: Field Study Perspectives.
[10] Markovitz, H., 1959. Portfolio Selection: efficient diversification of investments. Wiley, New York.

[11] Lintner, J., 1965. The valuation of risk assets and the selection or risky investment in stock portfolios and capital budgets. Rev. Econom. Statist., 47: 13--37.

[12] Soenen, L.A., 1981. Valutabeheer. Het Spectrum (in Dutch). 